\title{
Tarımsal Atıklardan Biyogaz Üretimi İçin Anaerobik Fermentör Tasarımında Etkili Etmenler
}

\author{
Gökhan Türker* \\ ${ }^{1 *}$ Kadir Has Üniversitesi, Doğa Bilimleri ve Mühendislik Fakültesi, Biyoenformatik ve Genetik Bölümü, İstanbul, Türkiye, (ORCID: 0000-0001-8073-5151), \\ gokhan.turker@khas.edu.tr
}

(İlk Geliş Tarihi 24 Ağustos 2020 ve Kabul Tarihi 14 Aralık 2020)

(DOI: 10.31590 /ejosat.784599)

\begin{abstract}
ATIF/REFERENCE: Türker, G. (2021). Tarımsal Atıklardan Biyogaz Üretimi İçin Anaerobik Fermentör Tasarımında Etkili Etmenler. Avrupa Bilim ve Teknoloji Dergisi, (21), 181-190.

$\ddot{\mathbf{O z}}$

Biyogaz üretmek amacıyla, kullanılacak materyalin belirlenmesi süreçlerini iyileştirmek ve hızlandırmak için, bu materyallerin çeşitli ortak özelliklerine uygun fermentör tasarımları gereklidir. Anaerobik fermentasyon işleminde tarımsal biyokütle kullanımındaki en büyük sorun, üretim sistemlerinin farklı olması nedeniyle, materyal boyutları ve bileşimlerinin değişken olmasıdır. Fermentör tasarımı, metan verimini ve anaerobik fermentasyon sürecini etkileyen önemli bir etmendir. Fermentör tasarımında etkili etmenler esas olarak, kullanılacak hammaddenin özellikleri ve işletme değişkenleri olmak üzere iki temel grupta incelenebilir. Ticari ölçekli anaerobik fermentörler, izleme ve kontrol sistemlerinin yetersiz olması nedeniyle, genellikle uygun yükleme oranlarının (OYO) altında çalıştırılmaktadır. Bu durum, metanojenleri etkileyen yüksek oranda uçucu yăg asitleri (UYA) gibi, inhibitör bileşikler oluşturarak, fermentasyon sürecinde kararsızlığa neden olabilir. Fermentörlerin arızalanma oranı, düzensiz akışlı ve sürekli karıştırılan tip fermentörlerde yüksek düzeylere ulaşmıştır. Fermentörler için uygun çalışma koşullarının sürdürülebilmesi için, otomatik ölçme ve kontrol sistemlerinin kullanılması önemlidir. Bu çalışmada, anaerobik fermentör tasarımında etkili; biyolojik, teknik, ekonomik ve çevresel ölçütler değerlendirilmiştir.
\end{abstract}

Anahtar Kelimeler: Biyogaz üretimi, Fermentör tasarımı, Tarımsal atıklar

\section{Design Factors for Anaerobic Fermenter in Biogas Production From Agricultural Wastes}

\begin{abstract}
For biogas production, in order to improve and speed up the process of determining the material to be used, fermenter designs suitable for various common features of these materials are required. The biggest problem in the use of agricultural biomass in the anaerobic fermentation process is that the material sizes and compositions are variable due to the different production systems. Fermenter design is an important factor affecting methane yield and anaerobic fermentation process. Effective factors in fermenter design can be examined in two basic groups, mainly the properties of the raw material to be used and operating variables. Commercial-scale anaerobic fermenters are generally operated below the appropriate loading rates (OLR) due to insufficient monitoring and control systems. This can lead to instability in the fermentation process by creating inhibitory compounds such as highly volatile fatty acids (VFAs) that affect methanogens. The rate of failure has reached high levels in plug flow and continuously stirred type fermenters. It is important to use automatic measurement and control systems to maintain suitable working conditions for fermenters. In this study, biological, technical, economical and environmental factors have been evaluated for fermenter design
\end{abstract}

Keywords: Biogas production, Fermenter design, Agricultural wastes

\footnotetext{
*S Sorumlu Yazar: Gökhan Türker, ORCID: 0000-0001-8073-5151, gokhan.turker@khas.edu.tr
} 


\section{Giriş}

Kırsal alanlarda, bitkisel ve hayvansal ürünlerin yoğun olarak üretim sonucunda her yıl bol miktarda kalıntı oluşmaktadır. $\mathrm{Bu}$ atıkların bir kısmı kullanılmakla birlikte, artıkların önemli bir bölümü kullanılmamaktadır. $\mathrm{Bu}$ atıklar, farklı özelliklere sahiptirler ve dağınık yerlerde kalırlar. Dünyada her yıl büyük miktarlarda ürün kalıntısı üretilmekte ve genellikle açık çevreye dökülmektedir. Bu atıklar genellikle, tahıl ürünleri samanı, pirinç kabuğu, küspe, mısır koçanı, hindistancevizi kabuğu, yer fistığı ve diğer fındık kabukları ve talaştır. Mısır, buğday, pirinç ve şeker kamışı ürünlerinden her yıl fazla miktarda biyokütle atık oluşur. Bununla birlikte, bu atıkların önemli bir bölümü hayvanlar için yem olarak kullanılır. Bununla birlikte, bu biyokütlenin büyük bir kısmından yararlanılmamakta ve açık alanlarda yakılmaktadır. Çeltik kabuğu ve şeker kamışı küspesi genellikle bir yerde büyük miktarlarda birikir. Çeltik kabuğu en yaygın tarımsal kalıntılar arasındadır. Geniş tarım alanları ile çevrili büyük şehirlerde, açık havada çeltik kabuğu yakılması önemli sorunlar yaratır.

Biyogaz üretimi, 1950'li yıllarda dünya genelinde başlatılmış olsa da, kırsal bölgelerde yaşayan insanlar arasında biyogaz üretim teknolojileri konusunda farkındalık bulunmaması tasarımlanacak biyogaz tesislerinin; teknik, ekonomik ve çevresel özellikleri anlatılmıştır.

\section{Materyal ve Metot}

\subsection{Anaerobik Fermentasyon Sistemleri}

En basit tasarımdaki bir anaerobik fermentasyon sisteminde, dört fermentasyon aşamasının tamamının gerçekleştiği bir adet fermentör bulunur. Buna tek aşamalı fermentasyon sistemi denir. Bununla birlikte, bilim ve biyoteknolojinin gelişmesiyle birlikte, bilim adamları her fermentasyon aşamasının farklı ve en iyi gelişen koşullara sahip olduğunu bulmuşlardır. $\mathrm{Bu}$ nedenle, fermentasyon aşamalarının (çok aşamalı fermentasyon) fiziksel olarak ayrılmasıyla, her bir aşamanın en yüksek dönüşüm verimliliğine ulaşmak için optimize edilmesi amaçlanmıştır. Günümüzde, çok aşamalı fermentasyon sistemleri sadece iki aşamalı ve üç aşamalı sistemleri kapsar. İki aşamalı sistemde, iki farklı fermentörde hidroliz ve metanojenez aşamaları gerçekleşir. Daha karmaşık olan üç aşamalı sistemde ise, çeşitli fermentörlerde hidroliz, asidojenez/asetojenez ve metanojenez aşamaları gerçekleşir. AD sistemleri, Şekil 1'de gösterildiği gibi, kullanılan fermentörün tipine göre (yaş veya kuru) sınıflandırır.

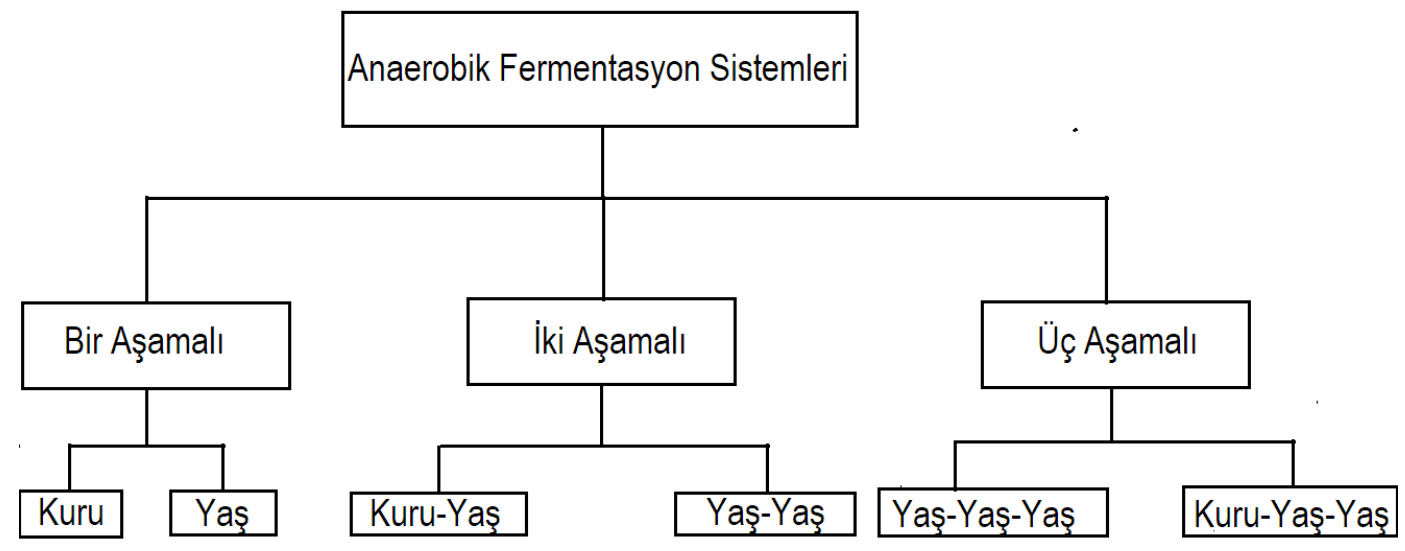

Şekil 1. Anaerobik fermentasyon sistemlerinin sınıflandırılması

nedeniyle, Hindistan gibi ülkelerde uygulanabilir biyogaz üretimi sağlanamamıştır. Ayrıca, biyogaz üretimi için uygun teknolojilerin azlığı, Hindistan'da biyogaz temelli uygulamaların uygulanmasını sınırlamaktadır. Biyogaz, aynı zamanda pişirme için kullanılan geleneksel yakıtlara kıyasla ucuz bir yakıttır. Mutfak atığı ve sığır gübresi karışımı uygulanabilir gaz üretimi elde etmek için çok önemlidir. Çünkü sığır gübrelerinin mevcudiyeti, konutlar için biyogaz üretiminin genişlemesindeki ana endişelerden biridir. Çeşitli biyolojik atıkların bileşimi, herhangi bir sistemin genel verimliliğine etki eder. Günlük sabit yükleme hızı, farklı materyallerin dengeli karıştırılması ve hidroliz ve asitleşme fazlarının metanlaşma fazından ayrılması, biyogaz verimini ve kalitesini en üst düzeye çıkaran önemli faktörlerdir.

Organik kökenli atıklar, anaerobik fermentasyon sistemleri kullanılarak, yenilenebilir bir yakıt olarak, metan gazına dönüştürülebilir. Bir tarım işletmesinde günlük faaliyetler sırasında, farklı türde birçok atık açığa çıkar. Bunlar, tarımsal üretimden kaynaklanan sığır gübresi ve mısır sapları gibi ürün kalıntılarından oluşan hayvansal ve bitkisel kökenli sıvı veya katı atıklardır. $\mathrm{Bu}$ konuda kapsamlı araştırmalar yapılmaktadır (Eryılmaz ve Ark., 2015; Kocabey, 2019; Zenk, 2019; Kanat ve Ergüven, 2020). $\mathrm{Bu}$ çalışmada; tarımsal işletmeler için

\subsubsection{Bir Aşamalı Sistemler}

$>$ pH değeri: 6,8-7,4

$>$ Hidrolik Bekleme Süresi (HBS) mezofilik sıcaklıkta 30 gün, termofilik sıcaklıkta 20 gün ve psikrofilik sicaklıkta 50 gün

\subsubsection{Bir Aşamalı Yaş Sistemler}

Yaş fermentör kullanılan tek aşamalı sistemlerdir. Organik yükleme oranlarına (OYO) bağlı olarak iki gruba ayrılırlar (Ramos-Suárez ve Ark., 2015, Turker, 2020):

1) Düşük oranlı sistemler (OYO $=0,5-1,6 \mathrm{~kg}$ vs $/ \mathrm{m}^{3}$ gün $)$

2) Yüksek oranlı sistemler (OYO $\left.=1,6-4,8 \mathrm{~kg} \mathrm{vs}_{\mathrm{V}} / \mathrm{m}^{3} \mathrm{gün}\right)$.

Bazı araştırmalarda, bu tip sistemlerin SAN gibi inhibitörlere karşı duyarlı oldukları belirlenmiştir. Duan ve Ark., (2012) SAN düzeyi $>0,6 \mathrm{mg} / \mathrm{L}$ koşulunun, sistem kararlılığını etkileyen en önemli etmen olduğunu belirtmişlerdir. Serbest Amino Nitrojeni (SAN) konsantrasyonu 1,45 g/L düzeyine yükseldiğinde, metan veriminin \% 50 oranında azaldığı bildirilmiştir (Nakakubo ve Ark., 2008). Yen ve Brune (2007), SAN 1,7-1,8 g/L aralığına yükseldiğinde sistemin başarısız olabileceğini bildirmişlerdir. 
Düşük Hızlı Yaş Sistem: Düşük hızlı yaş sistem en eski ve en basit sistemdir. Başlıca özellikleri şunlardır:

- Bekletme süresi (BS) uzundur (BS=30-60 gün)

- Karıştırma işlemi zayıftır.

- Isitma uygulanmaz.

Çok basit olan bu sistem, ancak çok düşük verimlilikte olan düşük hızlı sistemler sadece Çin, Hindistan ve Vietnam gibi gelişmekte olan ülkelerde, konut ve çiftlik ölçeğinde kullanılmaktadır. Bu tip sistemlerin çalışma ilkesi Şekil 2 (a)'da gösterilmiştir. Küçük veya büyük ölçekli olması önemli olmadan, dört bölgeli fermentörde her zaman tabakalaşma gerçekleşir:

1) Köpük tabakası

2) Sıvı tabakası (veya yüzer tabaka)

3) Fermente olan katı tabakası

4) Fermente olmuş katı tabakası

$\mathrm{Bu}$ sistemler arasında, konut ölçeği (Şekil 2 (b)) aynı zamanda yüzer kubbeli fermentörü veya sabit kubbeli fermentör olarak da bilinir. Hacimleri 1-8 $\mathrm{m}^{3}$ aralığında olmasına rağmen, en yaygın kullanılan sitemlerin hacimleri $1-3 \mathrm{~m}^{3}$ aralığındadır. $\mathrm{Bu}$ sistemlerde günlük besleme oranı, fermentör hacminin yaklaşık 1/40-1/50 arasındadır (Abbasi ve Ark., 2011). Bir lagün fermentör, (Şekil 2 (c)), çiftlik ölçeğinde aşağıdaki koşullarda çalıştırılır (Tchobanoglous ve Ark., 2003):

- $\quad \mathrm{HBS}=30-60$ gün aralığında

- $\quad C Y=50-100$ gün aralığında

- $\quad \mathrm{TS}=\% 0,5$ ile 5 aralığında tankından ayrılır ve biyokütle konsantrasyonunun VS $=\% 5-10$ aralığında tutulduğu fermentöre geri pompalanır (Burton ve Stensel, 2014). Anaerobik temas (AC) sistemi (Şekil 5.7b) OFMSW için kullanılır. Bu sistemde taze materyal, TS $=\% 10-15$ düzeyine ulaşmak için su ile karıştırılır. Verimliliğin 100-150 $\mathrm{m}^{3}{ }_{\text {biyogaz }} /$ ton $_{\text {attk }}$ olması ve TS düzeyinin $\%$ 50-60 azalması ile $\mathrm{OYO}=4-8 \mathrm{~kg} \mathrm{vs} / \mathrm{m}^{3}$ gün düzeyine ulaşabilir (Rapport ve Ark., 2008).

Hammaddenin materyali esas olarak çözünür durumda (veya TS <\% 3-5) olduğunda, aşağıdaki fermentörler tasarımları kullanılabilir:

- Yukarı akışlı anaerobik bulamaç yataklı fermentör (UASB)

- Genişletilmiş granül bulamaç yataklı fermentör (EGSB)

- Genişletilmiş yatak fermentör (EB)

- Akışkan yataklı fermentör (FB)

- İç dolaşımlı fermentör (IC)

- Anaerobik sabit yataklı fermentör (AFB)

$\mathrm{Bu}$ tasarımlardaki fermentörlerin çalışma ilkeleri ve özellikleri önceki bölümlerde açıklanmıştır. Bu tip fermentör tasarımları, endüstriyel atıksu arıtma sektöründe yaygın olarak kullanılmaktadır.

\subsubsection{Bir Aşamalı Kuru Sistemler}

Katı içerikleri fazla olan hammaddeler, yaş fermentasyon sistemlerinde kullanılabilir. Ancak, çok miktarda su ilave edilmesi gerekir. Atık akımının seyreltilmesi sadece daha yüksek su ve enerji tüketimi maliyeti değil, aynı zamanda daha yüksek hacimli

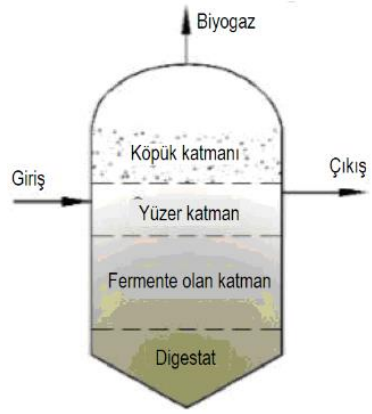

(a) Dưşük hızı fermentör

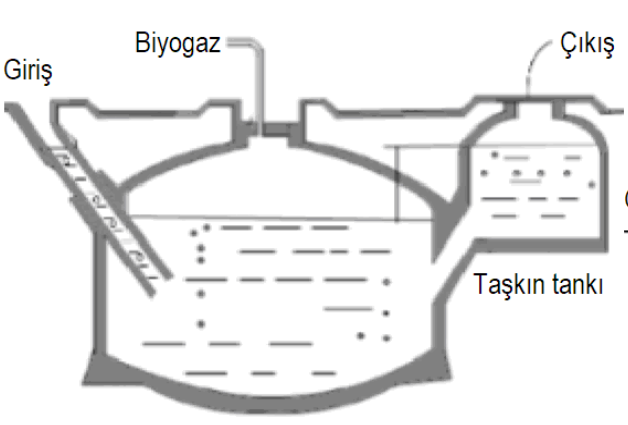

(b) Konut tipi fermentör

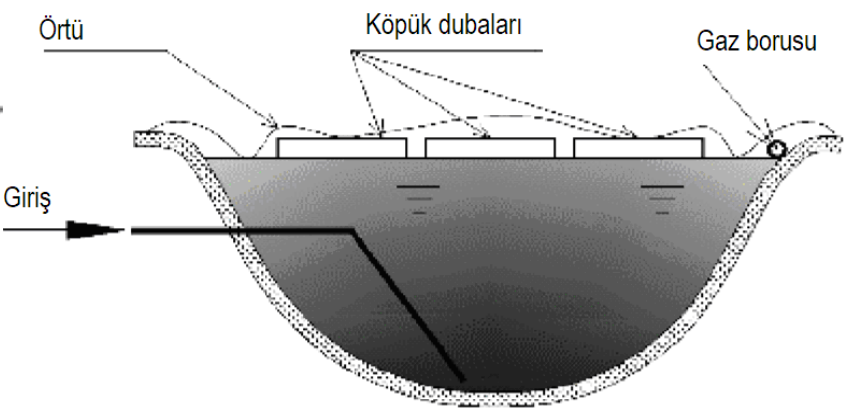

(c) Lagun fermentör

\section{Şekil 2. Bakterilerin asılı büyüdüğü yaş fermentör tasarımları}

Yüksek Hızlı Yaş Sistem: Yüksek hızlı yaş sistemler, verimliliklerini artırmak için düşük hızlı fermentörlerden geliştirilmiştir. Hammadde materyali, uygun bir ortam oluşturmak için 1sıtılabilir ve karıştırılabilir. Bu durum fermentörün daha az hacim, daha kararlı ve daha verimli olmasını sağlar (Turovskiy ve Mathai, 2006) Yüksek hızlı yaş sistemlerin ilk kuşağı, bir 1sı kaynağı tarafından desteklenen piston akışlı yaş fermentörlerdir (WPF). Bu sistem, en çok TS = \% 11-14 ve HBS = 15-20 gün arasında olan gübre için uygulanmıştır. Tamamen karıştırılan fermentör (CMR) veya sürekli karıştırılan tank tipindeki fermentör (CSTR) olarak adlandırılan daha karmaşık bir fermentör, iç kısmında karıştırma uygulaması gerektirir (Şekil 3a). $\mathrm{Bu}$ sistem genellikle $\mathrm{OYO}=1,5-5 \mathrm{~kg} \mathrm{vs}_{\mathrm{v}} / \mathrm{m}^{3}$ gün ve $\mathrm{BS}=$ 15-20 gün arasında mezofilik sıcaklıkta çalışır (Abbasi ve Ark., 2011). CSTR'de, bakteriler atık sıvı ile birlikte fermentörden yıkanır. Daha yüksek OYO düzeyine ulaşmak için, fermentörün içinde daha yüksek bir bakteri konsantrasyonuna gereksinim vardır. $\mathrm{Bu}$ nedenle, çıkış suyunun biyokütlesi bir çöktürme bir fermentör gerektirir. Ayrıca, atıkların seyreltilmesi biyogaz verimini azalmasına ve daha fazla atık su üretilmesine neden olabilir. Bu nedenle, kuru fermentörler katı içeriği yüksek olan atıklar için geliştirilmiştir (Şekil 4). Yaş sistemlere kıyasla kuru sistemlerin çalıșması ile ilgili olarak başlıca sorunlar şunlardır:

$>$ Yüksek viskoziteli materyalin karıştırılması

$>$ Yüksek viskoziteli materyalin pompalanması

Teknolojilerin gelişimiyle birlikte, bu tür sorunlar giderek azalmıştır. Günümüzde Avrupa'da Dranco, Valorga, Kompogas ve Biocell firmaları, pilot ölçekli uygulamalar yapan başlıca firmalardır. Genel olarak kuru sistemler, aşağıdaki koşullardaki kararlılıkları nedeniyle yaş sistemlerden daha güçlüdürler:

$>$ Amonyak konsantrasyonu 2,5-3 g/L düzeyine kadar

$>\mathrm{UYA}=23-24 \mathrm{~g} / \mathrm{L}$ aralığında 


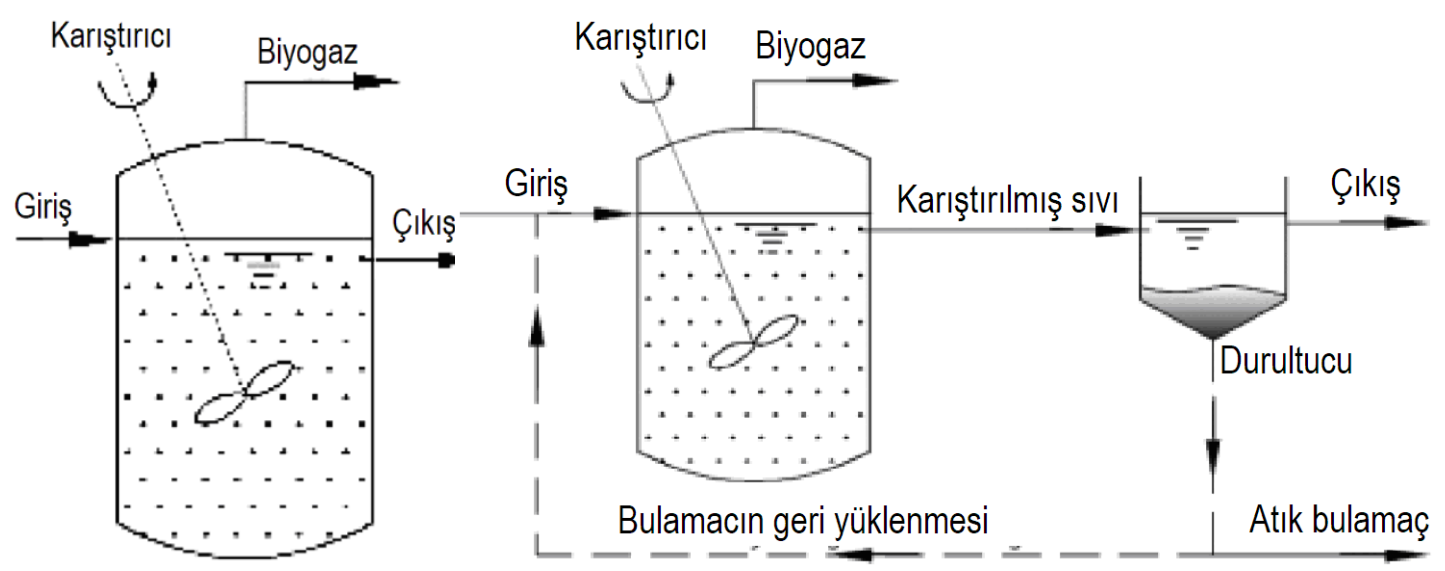

(a)

(b)

Şekil 3. Karıştırmalı yaş fermentör tasarımları

Dranco sistemi, piston akışlı dikey bir fermentördür (Şekil 4a). Bu sistemde, digestatın bir kısmı karıştırma pompasına geri alınır. Aşılama için 6-8:1 oranında taze materyal (partikül büyüklüğü $<4 \mathrm{~cm}$ ) ile karıștırılır. Bundan sonra, karıșım fermentörün üst kısmına yerleştirilir ve aşağı doğru konik bir tabana doğru hareket eder. Burada bir helezon konveyör digestatı çıkarır. Digestatın geri kalanı, kompost haline getirilmeden önce, suyu alınır. Fermentör içinde aktif karıştırma yoktur. Bu durumda, eksik fermentasyon nedeniyle, biyogazın \% 20-30'u kaybedilebilir (Trzcinski ve David, 2017). Sistemin, TS $=\%$ 20-50 arasında değişen katı atıkların fermentasyonunda başarılı olduğu kanıtlanmıştır (Lisseens ve Ark., 2001). OFMSW (TS\% 30-45), mezofilik koşullarda HBS = 20 gün işlendiğinde, VS \% 55 oranında azalır ve OYO $5-8 \mathrm{~kg}_{\mathrm{vS}} / \mathrm{m}^{3}$ gün arasındadır (Trzcinski ve David, 2017). Termofilik sıcaklıkta 14 gün bekletme süresi ile $\mathrm{OYO}=15 \mathrm{~kg} v \mathrm{~s} / \mathrm{m}^{3}$ düzeyine çıkabilir ve VS'nin \% 65'i yok edilebilir (Rapport ve Ark., 2008). OFMSW fermentasyonu için, alkali katkı maddesi genellikle gereksizdir ve fermentörün içindeki $\mathrm{pH}$ düzeyi yaklaşık 8 'dir. Her ton atık $120-170 \mathrm{~m}^{3}$ biyogaz (200 kWh enerjiye eşdeğer) üretebilir. Tesis üretilen bu enerjinin \% 30-40'1nı tüketir ve geri kalanı farklı amaçlar ile kullanılabilir.

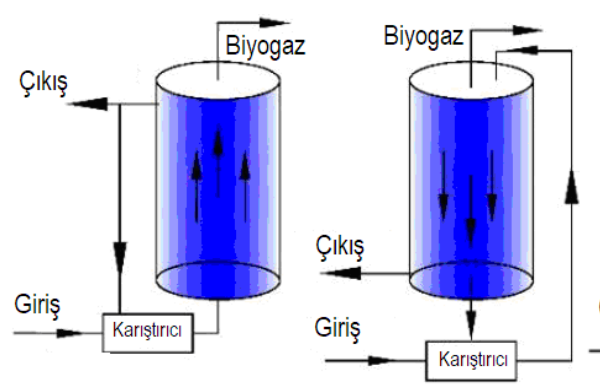

(a)

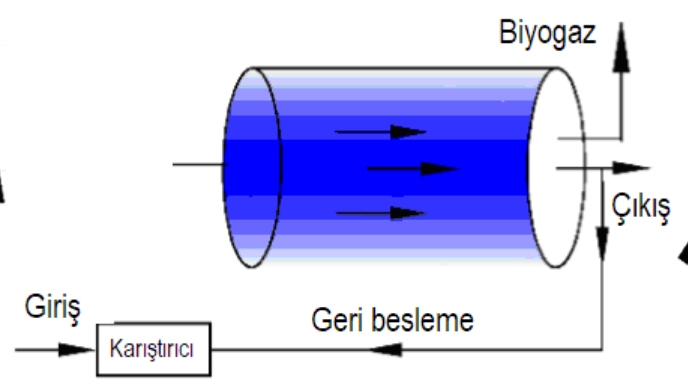

(b) termofilik koşullarda $\left(55-60{ }^{\circ} \mathrm{C}\right)$ çalışır. Dijestat, bir helezon götürücü kullanılarak suyu alınır. Daha sonra katı kısım, havalandırılarak 2-3 hafta kompostlaştırılır. Sistem bir ton atıktan 130-150 $\mathrm{m}^{3}$ biyogaz, $500 \mathrm{~kg}$ kompost ve $300 \mathrm{~L}$ siv1 gübre üretebilir.

Valorga sisteminde piston akışlı dikey fermentör kullanılır. Hammadde, gelen atık akımı (boyut $<30 \mathrm{~mm}$ ) ile TS değeri \% 25-30 aralığında ayarlanmış digestat karışımıdır. TS konsantrasyonu \% 20'den az ise, tanecikli parçacıklar hızla dibe çöker ve dolaşan gaz gözeneklerini tıkar. Sistem, VS uzaklaştırma oranı \% 50 değeri ile 1 ton atıktan yaklaşık $140 \mathrm{~m}^{3}$ biyogaz üretir (Kayhanian ve Ark., 2007). OFMSW için içerideki pH genellikle 7,8-8 arasındadır. $\mathrm{Bu}$ nedenle, alkali katkı maddesi gerekli değildir. pH düzeyi düştüğünde, besleme pompası süreç kendini düzenleyene kadar durmalıdır. Biyogaz ürününün bir kısmı, karıştırma amacıyla ve malzemelerin askıda tutulması için fermentörün tabanına yüksek basınçla ( 5 bar) geri enjekte edilir. Sistem, genellikle $\mathrm{BS}=18-23$ gün ile mezofilik sıcaklıkta çalıştırılır. Biyogaz verimi 220-270 L/ $\mathrm{kg}_{\mathrm{VS}}$ aralığındadır. Fermentasyon işleminden sonra, dijestat 2-3 hafta sürede kompostlaştırılır.

Şekil 4. Kuru fermentör tasarımları

Kompogaz sisteminde, hammaddeden gaz üretimine ve homojenleştirilmesine yardımcı olmak için dâhili rotorlu piston akışlı yatay bir fermentör (Şekil 4 b) kullanılır. Kullanılan hammadde (partikül boyutu $<50 \quad \mathrm{~mm}$ ) sistem akışının düzenlenmesi amacıyla, TS=\% 23-28 aralığına ulaşmak için dijestat sıvısı ile karıştırılır. Daha yüksek TS değerlerinde, çok yüksek viskozite nedeniyle, karışımın akışı zordur. Daha düşük TS değerleri fermentörün içinde kum ve cam birikmesine neden olur. Sistem genellikle, HBS = 14-20 gün bekletme süresi ile
Kuru kesikli fermentasyon sistemi (Şekil 4 c), düzenli depolama sahaları örnek alınarak geliştirilmiştir. Bununla birlikte, depolama alanındaki doğal biyo-bozunmadan farklı olarak, kuru kesikli sistemdeki tepkime iki temel faktör tarafından hızlandırılmaktadır. Birincisi, sızıntı suyunun sürekli dolaşımıdır. Yüksek nemli bir ortamının oluşmasına ve inokulum ve substratların yayılmasına olanak sağlar. İkincisi, sistemdeki sıcaklığın optimum aralıkta kontrol edilmesidir. Bunun sonucunda, çöp sahalarında gözlemlenenden çok daha fazla 
biyogaz üretim hızı ve daha düşük BS gerçekleşir. Fermentör, taze materyal ile doldurulur ( $\mathrm{TS}=\%$ 30-40), boşaltılır ve daha sonra yeni bir parti ile doldurulur. Biyogaz üretimi durduğunda, fermentasyon süresi sona erer. Mezofilik sıcaklıkta 20 günden fazla fermentasyondan sonra, dijestat kompostlama için 1-3 hafta boyunca havalandırılır. Sistem, her bir ton atık için; $90 \mathrm{~kg}$ biyogaz (\% $58 \mathrm{CH}_{4}$ ), $455 \mathrm{~kg}$ atık su ve $310 \mathrm{~kg}$ kompost üretir (Nayono, 2010). Sürekli kuru sistemlere kıyasla, ekipman maliyetinden \% 40 oranında tasarruf edilmesine karşın, inşaat için daha geniş alana ihtiyaç duyulduğundan, kesikli kuru sistemler çok daha düşük uygulama oranına sahiptirler.

\subsection{2. İki Aşamall Sistemler}

\subsubsection{Iki Aşamalı Sistemlerin Tasarımı}

Hidroliz/asidojenez ve metanojenez aşamalarında büyüme özellikleri çok farklıdır. $\mathrm{Bu}$ nedenle, iki aşamalı fermentasyon, her fermentasyon aşamasını optimize etmek için geliştirilmiştir. Günümüzde, fermentasyon aşamalarının iki fermentöre ayrılması hakkında iki farklı görüş vardır. İlk görüşte, birinci tankın hidroliz/asidojenez aşamalarının gerçekleşmesine olanak sağladığı ve ikinci tankın asetojenez/metanojenez aşamalarını optimize ettiği kabul edilir. İkinci görüşte, asetojenez aşamasının birinci fermentörde oluşması ve ikinci fermentörün sadece metanojenez aşamasını optimize etmesi önerilmektedir. İkinci bakış açısı, asetojenez aşamasından en yüksek düzeyde hidrojen elde edilmesine yönelik olabilir. Ancak, bu fikir aşağıdaki nedenlerle geçerli değildir (Yu ve Ark., 2013):

$>$ Anaerobik fermentasyon işlemiyle hidrojen üretimi, ticari olarak kalite standartlarını karşılayabilmek için, hidrojen gazını zenginleştirmek amacıyla gereken yüksek maliyet nedeniyle, ekonomik olarak uygun değildir.

$>$ Metanojenler (hidrojen tüketicisi) ve asetojenler (hidrojen üreticisi) yakın işbirliği içinde çalışmalıdır.

$>$ Asetojenler aynı zamanda hassas ve katı anaeroblardır. Fakültatif bakterilerle (hidrolitik/asidojenik mikroorganizma) birlikte çalışmamalıdırlar. Aslında, fermentasyon aşamalarının kesin bir şekilde ayrılmasını sağlamak çok zordur. Bu nedenle, asetojenez her iki fermentörde de çoğunlukla ikincisinde meydana gelebilir.
İki aşamalı sistemlerin çalışma şeması Şekil 5'de gösterilmiştir. İki fermentör arasındaki farklı çevresel koşullar nedeniyle, hidrolize edilemeyen materyallerin uzaklaştırılması, pH'in kontrol edilmesi ve hatta organik konsantrasyonun kontrol edilmesi gibi birçok amaç için, Şekil 5'de gösterilen iki fermentör arasına genellikle bir tampon tank yerleştirilir. İki aşamalı sistemde, gerektiğinde bir, iki veya üç su dolaşım döngüsü (Şekil 5'de R1, R2 ve R3 ile gösterilen) kullanılabilir. Bu dolaşım döngülerinin kullanılması durumunda sağlanılan yararlar şunlardır:

$\checkmark \quad$ İkinci fermentörde yüksek alkaliniteli atıksu kullanılması nedeniyle asitlik azaltılarak, $\mathrm{pH}$ daha fazla kontrol edilir.

$\checkmark \quad$ Katı içeriği yüksek besleme materyali karıştırılır ve seyreltilir.

$\checkmark$ Bakterilerin aktiviteleri iyileştirilir.

Bununla birlikte, inhibitörler fermentörlerde birikir ve uzun süre kullanılması nedeniyle, sistemin kararsız duruma gelmesine neden olursa, gelen substrat tatlı su ile seyreltilmelidir. Hidrolizden sonra, hammaddenin katı içeriği önemli ölçüde azalır. $\mathrm{Bu}$ nedenle, iki aşamalı sistem kuru-yaş tasarım (birinci fermentörde yüksek katı ve ikinci fermentörde düşük katı) veya yaş-yaş tasarım (her iki kademe düşük katı) olabilir. Hidroliz/asidojenez için genellikle bir CSTR kullanılır. Metanojenez aşaması için, CSTR, UASB, AFB, FB, EB, IC ve EGSB dahil olmak üzere yüksek hızlı yaş fermentörler kullanılır.

\subsubsection{Hidrolitik/Asidojenik Fermentör}

$\mathrm{Bu}$ fermentörün işlevi, inhibe edilmekten ve aşırı yüklenmeden kaçınarak, materyali UYA'lara mümkün olduğunca hızlı bir şekilde dönüştürmektir. Bu nedenle; $\mathrm{pH}$, sıcaklık, asit konsantrasyonu, besinler ve substrat konsantrasyonunu (TS) gibi birçok çalışma koşulu kontrol edilmelidir. OFMSW gibi katı içeği yüksek atıklar için, atık akımı fermentöre verilmeden önce parçacık boyutunu $(<15 \mathrm{~mm})$ küçültmek için parçalanmalıdır. Hidroliz/asitojenez genellikle karıştırma tanklarında yeterince hızlı ilerler. $\mathrm{Bu}$ nedenle hidroliz/asitojenez için başka bir fermentör geliştirilmemiştir. Karıştırılan fermentörler arasında CSTR'ler yaygın olarak, piston akışlı yaş fermentör ise bazı durumlarda kullanılır.

İkinci Fermentör

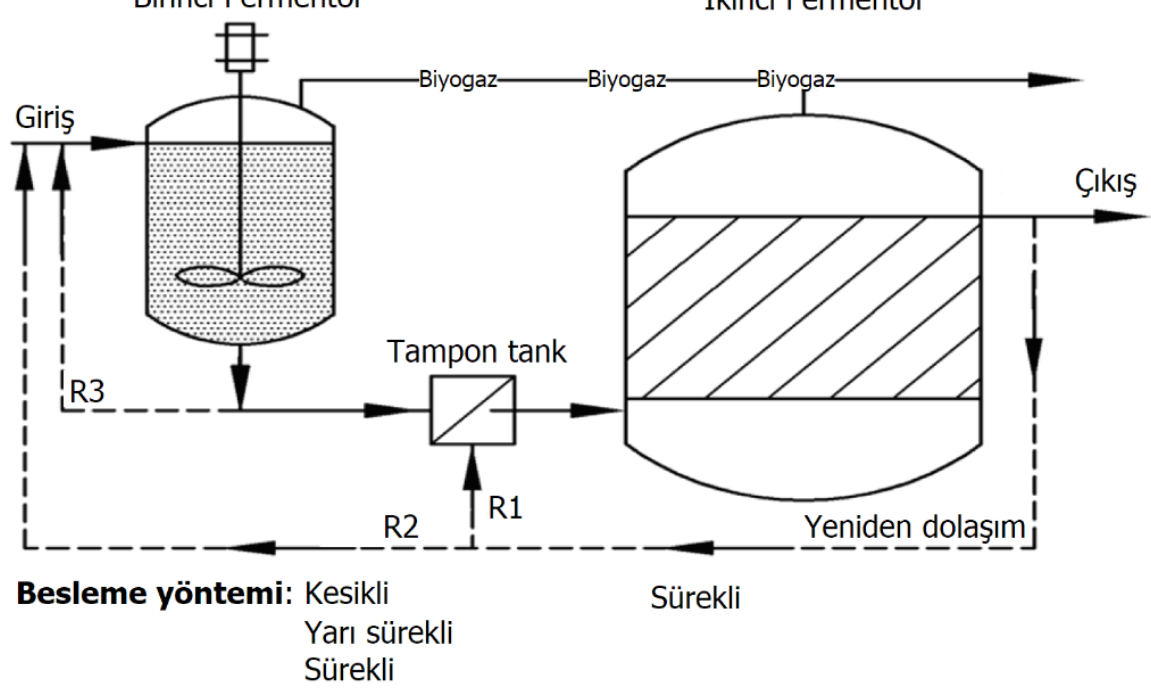

Fermentör tipi: Tam karıştırmalı

CSTR, UASB, AFB, FB, EB, IC, EGSB

Şekil 5. İki aşamalı fermentasyon sistemlerinin akış şeması 
Toplam Katı Madde: Katı içerikleri yüksek olan hammaddelerin hidrolize edilmesi, fermentörün daha yüksek kapasitede çalışmasını sağlar. Isıtma için daha az enerji ve daha az su tüketimi gerektirir. Bununla birlikte, çok yüksek bir katı içeriği, karışımların viskozitesinin yüksek olmasına neden olabilir. $\mathrm{Bu}$ durum, yetersiz karıştırmaya veya karıştırma işleminin çok fazla enerji tüketmesine neden olabilir. Ayrıca, katı içeriğinin (\% 5-40 aralığında) artması inhibitörlerin ve çözünmeyen katı içeriğinin artmasına neden olur. Bu durum, hidrolitik dönüşüm oranının azalmasına neden olur. Ayrıca, yüksek katı madde konsantrasyonu (TS $>\%$ 15) normalden çok daha uzun bekletme süresi ( $\mathrm{BS}=10-15$ gün) gerektirir (Ostrem, 2004). Bu nedenle, karıştırılan tip bir fermentör kullanılması durumunda, hidroliz/asidojenez aşaması için hammaddede TS içeriğinin \% 15-20 aralığında olması, genellikle üst sınır olarak kabul edilir (Rosgaard ve Ark., 2007).

pH Değeri: Moestedt ve Ark., (2016) 4,5'in altındaki pH değerinin hidrolitik/asidojenik fermentörde 15 güne kadar HBS gerektirdiğini bildirmiştir. $\mathrm{pH}$ değeri 4'ten 5,5 değerine yükseltildiğinde, materyalin çözünürlüğü ve asitleşmesi önemli ölçüde artar (Yu ve Fang, 2002). Alkali koşullar altında, Zhang ve Ark., (2005) pH değeri 7'den 11'e yükseldiğinde, UYA oluşumunun önemli ölçüde azaldığını bildirmişlerdir. $\mathrm{pH}>10$ olması durumu, mikroorganizmaların aktivitesinde geri dönüşü olmayan bir kayba neden olmaktadır (Deublein ve Steinhauser, 2011). pH değerlerinin 5,5 ve 6,5 arasında olması, çoğu zaman en uygun aralık olarak belirtilmiştir ve en uygun $\mathrm{pH}$ değerleri 6,0 'dır (Lindner ve Ark., 2015). Bu pH değerleri, her hidroliz ve asidojenez aşaması için kabul dilebilir.

Sıcaklık: Birçok araştırmada, hidrolitik/asidojenik oranın sıcaklık artışıyla orantılı olarak arttığı belirlenmiştir. Ayrıca, mezofilik koşullara kıyasla, termofilik koşullar fermentör ve çevre üzerinde ciddi bir etkisi olabilecek patojenlerin zarar görmelerini artırır (Kim ve Ark., 2003). Bu nedenle, termofilik sicaklık mezofilik sıcaklıktan daha iyi görünmektedir. Bununla birlikte, Kozuchowska ve Evison (1995), mezofilik işlemlerin kahve atıklarının asitleştirilmesinde termofilik işlemden daha kararlı bir koşul sağladığını bildirmişlerdir. Komemoto ve Ark., (2009), gıda atıklarının çözünürlük oranının, mezofilik koşullarda diğerlerinden önemli ölçüde daha yüksek olduğunu bildirmişlerdir. Bu nedenle, enerji ve verimlilik ile ilgili olarak, organik atığın hidroliz/asidojenez aşamaları için $35-37{ }^{\circ} \mathrm{C}$ aralığındaki mezofilik sıcaklık tercih edilir.

Bekletme Süresi: Bu fermentördeki bekletme süresi, sadece çevresel koşullara değil, aynı zamanda atık özelliklerine de bağlıdır. OFMSW'nin (TS = \% 8,2) hidroliz/asidojenezi aşaması için, mezofilik sıcaklıkta bekletme süresinin 2-5 gün aralığında olması önerilmektedir (Pavan ve Ark., 2000). Gıda atığı için mezofilik sıcaklıkta bir günlük bekletme süresinin çok uygun olduğu bildirilmiştir (Paudel ve Ark., 2017) Tarımsal endüstriyel atık su için, $\mathrm{BS}=0,75$ gün bekletme süresinde asidojenez verimliliği en yüksek düzeye ulaşmıştır (Dareioti ve Kornaros, 2014). Genel olarak, mezofilik sıcaklıkta katı içerikleri yüksek olan materyaller için 2-5 gün arasındaki bekletme süresinin kullanılması tercih edilir (Turovskiy ve Mathai, 2006, Akyol ve Ark., 2016). Fermentörün kesikli olarak çalıştırılması durumunda, BS = 7-12 gün arasında olmalıdır (Yu ve Ark., 2006).

Besin Maddeleri: Hidroliz/asidojenez aşaması için, besin maddesi ve iz element gereksinimleri konusunda az sayıda araştırtma yapılmıştır. Deublein ve Steinhauser (2011), hidroliz/asidojenez aşaması için C/N oranının 10-40 aralığında olması gerektiğini bildirmişlerdir.

\subsubsection{Metanojenik/Asetojenik Fermentör}

Metanojenez/asetojenez aşamasında genellikle CSTR, UASB, AFB, FB, EB, IC ve EGSB gibi yüksek hızlı yaş fermentörler kullanılır. Bu fermentörler, zorunlu anaerobik olan ve sıcaklık, $\mathrm{pH}$ ve ayrıca BS değişimlerine duyarlı olan metanojen açısından zengin anaerobik ortam ile korunmalıdır. $\mathrm{Bu}$ nedenle, ikinci fermentördeki çalışma koşullarına kesinlikle uyulmalıdır.

Katı Madde İçeriği: Metan fermentörüne gelen materyalin TS değeri, kullanılan fermentörün tipine bağlıdır. CSTR veya CMR kullanılması durumunda, materyalin TS oranı \% 10'a kadar olmasına izin verilir. AFB fermentörü, daha düşük katı içeriğine ihtiyaç duyar (TS $\leq \%$ 5) (Roos ve Ark., 2004). UASB, EB, FB, EGSB ve IC fermentörler, içerideki biyokütle konsantrasyonunun \% 3,5-4 aralığında tutulması durumunda, daha düşük katı içeriği (TS $\leq \% 3$ ) gerekir (Burton ve Stensel, 2014).

pH Değeri: Metanojenler ve asetojenler için optimal pH durumu aralığı birbirine çok yakındır. Ayrıca asetojenler, metanojenlerden daha güçlüdürler. Bu nedenle, metanojenler için pH koşulunun optimize edilmesi, asetojenlerin büyümesini etkilemez. Aslında, 7,0-8,0 aralığındaki $\mathrm{pH}$ değerleri yaygın olarak kullanılır. Ayrıca, bu aşama, asitleri biyogaza dönüştüren bir alkalinizasyon işlemidir. $\mathrm{Bu}$ nedenle, bu fermentördeki materyalin $\mathrm{pH}$ değeri yukarıdaki aralıktan daha düşük olmalıdır. Fermentör içindeki pH, 6,5 değerinin altına düştüğünde, $\mathrm{pH}$ değerini ayarlamak için işlemin durdurulmalıdır (Von ve Ark., 2020).

Sıcaklık: Mezofilik ve termofilik koşullar altında, metanojenik bakteriler için en uygun sıcaklık sırasıyla, $35-37{ }^{\circ} \mathrm{C}$ ve $55^{\circ} \mathrm{C}$ 'dir (Zhang ve Ark., 2006). Li ve Ark. (2017) ve Pavan ve Ark. (2000), MSW'nin fermentasyonunu, hidroliz aşamasında aynı koşullarda, metanojenez aşamasında farklı sıcaklıklarda gerçekleştirmişlerdir. Li ve Ark. (2017), $710 \mathrm{~mL}_{\mathrm{CH} 4} / \mathrm{g}_{\mathrm{Vs}}$ elde etmek için $37{ }^{\circ} \mathrm{C}$ sıcaklıkta, fermetörü $\mathrm{HBS}=15$ gün ile çalıştırmışlardır. Diğer taraftan, Pavan ve Ark. (2000), aynı metan verimine ulaşmak için fermentörü daha yüksek bir sıcaklıkta (55 ${ }^{\circ}$ C) sadece için HBS=12,5 gün çalıştırmışlardır. Genel olarak, termofilik koşullarda biyogaz üretim oranları, mezofilik koşuldakine göre daha yüksektir. Bu nedenle, termofilik durumun kullanılması, OYO değerinin artmasını ve inşaat maliyetlerinden önemli düzeyde tasarruf edilmesini sağlar. Ancak termofilik metanojenler, çevresel değişime mezofilik anaeroblardan daha duyarlıdırlar. $\mathrm{Bu}$ nedenle, termofilik fermentör daha yüksek teknoloji gerektirir.

Bekletme Süresi ve Organik Yükleme Oranı: Yaş fermentör kullanıldığından bekletme süresi (BS) terimi, ÇY ve HBS'yi kapsar. ÇY değerlerinin, mezofilik durumda etkili bir verimlilik için, 20 günden daha fazla olması gereklidir ve termofilik sıcaklıkta ise 7-15 gün aralığında olmalıdır (Burton ve Stensel, 2014). HBS, ÇY'den daha kısadır ve hidrolitik ürünlere bağlı olarak birkaç saatten yaklaşık 20 güne kadar değişir. HBS, genellikle sicaklık ve OYO değerleri ile birlikte değerlendirilir. Turovskiy ve Mathai (2006) bulamaç arıtımı için mezofilik sıcaklıkta HBS'nin yaklaşık 10 gün olmasını önermişlerdir. Paudel ve Ark. (2017), FW ve kahverengi suyun birlikte fermentasyonu için metanojenik fermentörü, mezofilik sıcaklıkta, $\mathrm{HBS}=20$ gün, $\mathrm{ORL}=1,24 \mathrm{~g}$ vs/L/gün ile optimize etmişlerdir. Rincón ve Ark. (2008) zeytin yağı üretiminden açığa çıkan katı atıklar işlenirken, HBS $=17$ gün $\mathrm{OYO}=9,2 \mathrm{~g}$ COD $/ \mathrm{L} /$ gün 
değerlerinin uygun olduğunu bildirmişlerdir. Li ve Ark. (2017), MSW kullanarak mezofilik sicaklıkta, OYO $=3,8 \mathrm{~kg} \mathrm{vS} / \mathrm{m}^{3} \mathrm{HBS}$ $=15$ gün olması durumunda, $540 \mathrm{~mL} / \mathrm{g}_{\mathrm{vs}}$ biyogaz verimi elde edildiğini bildirmişlerdir. Bununla birlikte, Pavan ve Ark. (2000), MSW için termofilik durumda, aynı biyogaz verimi ile daha yüksek OYO $=5,7 \mathrm{~kg}$ vs $/ \mathrm{m}^{3}$ gün elde etmek için daha kısa bir HBS (7,7 gün) gerekli olduğunu bildirmişlerdir. Diğer taraftan, OFMSW'yi termofilik durumda fermente etmek için HBS = 8-9 gün arasında olması gerektiği önerilmektedir (Pavan ve Ark., 2000).

Besin Maddeleri ve Kısıtlar: Genel olarak, C:N:P oranının 75-150:5:1 değerlerinde olması gerektiği bildirilmiştir (Burton ve Stensel, 2014). Bununla birlikte, Lissens ve Ark. (2001) metanojenik fermentörün 10'un altında $\mathrm{C} / \mathrm{N}$ ile iyi çalıştığını belirtmişlerdir. Metanojenik inhibisyon, $\mathrm{pH}$ değeri 7,0'1n üzerinde tutmak için yeterli alkalinite olmasına rağmen, asetat konsantrasyonu $3 \mathrm{~g} / \mathrm{L}$ 'yi aştığında ortaya çıkmıştır (Burton ve Stensel, 2014). Metanojenlerin büyümesi için optimum kükürt konsantrasyonlarının literatürde 16 ile $160 \quad \mathrm{mg}_{\mathrm{S}} / \mathrm{L}$ arasında değiştiği bildirilmiştir (Uemura, 2010). Bu fermentörde toplam 3-7 g/L amonyak tolere edilebilir, ancak SAN toksisitesinin eşik değerlerinin 100-250 mg/L aralığında olduğu bildirilmiştir (Burton ve Stensel, 2014).

\subsection{3. $\ddot{U} c ̧$ Aşamall Sistemler}

\subsubsection{1. $\ddot{U} c ̧$ Aşamalı Sistemlerin Tasarımı}

İki aşamalı fermentasyon sistemlerindeki ikinci fermentörde, hem asetojenez hem de metanojenez aşamaları gerçekleşir. Diğer taraftan, asetojenler ve metanojenlerin, fizyolojik özellikleri ve besin gereksinimleri önemli düzeyde farklıdır. Aralarındaki büyüme dengesi, önemli inhibisyona neden olan çevresel değişiklikler nedeniyle kaybedilebilir.

$\mathrm{Bu}$ nedenle, hidroliz/asidojenez, asetojenez ve metanojenez aşamalarını çeşitli fermentörlere ayırmak için üç aşamalı fermentasyon kavramı geliştirilmiştir. Bununla birlikte, önceki bölümde tartışılan nedenlerden dolayı, her iki sürecin de ayrılması uygun bir yaklaşım değildir. Bu nedenle, Zhang ve Ark. (2016) ve Stewart (2014), ardışık olarak üç aşamalı fermentasyon modelini önermişlerdir:

1) Eksik hidroliz

2) Hidroliz/asidojenez

3) Asetojenez/metanojenez

$\mathrm{Bu}$ öneri, ilk fermentördeki hammaddenin hidrolitik oranını önemli ölçüde artıracaktır. $\mathrm{Bu}$ nedenle, ikinci öneri daha değerlidir. Aslında, gerçekte homojen olmayan metabolizma nedeniyle, üç aşamalı fermentasyondaki aşamaların dağılımı aşağıdaki gibidir:

1) Hidroliz / asidojenez,

2) Asidojenez / asetojenez

3) Asetojenez / metanojenez

Birinci ve ikinci fermentörlerde hidrojen elde edilebilir. Ancak önceki bölümde tartışıldığı gibi hidrojen üretimi ekonomik değildir. Üç aşamalı fermentasyon sisteminin akış şeması Şekil 6'da gösterilmektedir.

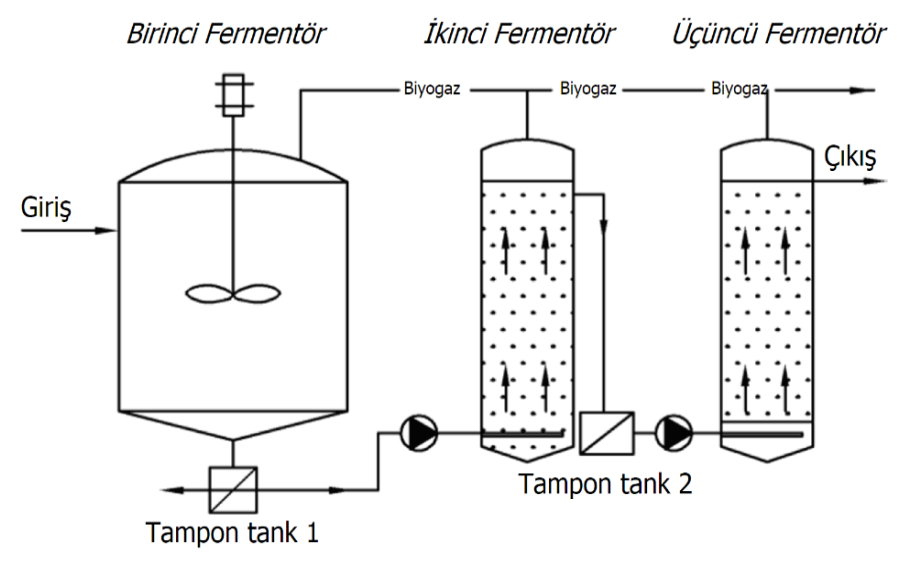

Sekil 6 Ï̈r asamalı anaerohik fermentasvon sistemi

\section{Araştırma Sonuçları ve Tartışma}

Tek aşamalı fermentör sistemlerinin geniş bir uygulama alanı vardır. Çok çeşitli organik atıklar kullanılabilir. Tek aşamalı fermentasyon sistemlerinde, güçlü bakteriler grupları (fakültatif mikroorganizmalar), aynı fermentörde yaşayan zayıf gruplar (metanojenler) kolayca geri püskürtebilir. $\mathrm{Bu}$ nedenle, besleme materyalinin; yük, pH ve katı konsantrasyonundaki değişimler, sistemin kararlılığına zarar verebilir. Asit oluşum hızı metan oluşum hızından daha fazlaysa, UYA birikimi olduğu anlamına gelir. Sistemin durdurulması ve kararlı duruma dönmesi için beklenmesi gerekir. $\mathrm{Bu}$ nedenle, iki aşamalı sistem, yukarıda belirtilen sorunlarla karşılaşmamak için en uygun çözüm olarak düşünülebilir.
İki aşamalı fermentasyon fikri, genel fermentasyonun ilerlemesini hızlandırmak için sadece hidroliz/asidojenez ve metanojenez aşamalarının her birini optimize etmekle kalmaz, aynı zamanda birçok yarar da sağlar. Metanojenler optimal ortamlarda büyürler. $\mathrm{Bu}$ durum, tek aşamalı fermentasyon sistemlerine kıyasla, metanojenlerin diğer gruplar tarafından işgal edilmelerinin daha zor olmasina neden olur. Bu nedenle, iki aşamalı fermentasyon sistemi, tek aşamalı olandan çok daha sağlamdır ve atık akışının değişmesi durumlarında iyi çalışabilir. Ayrıca, hidroliz/asidojenez aşamasında üretilen biyogaz ekonomik değildir. Daha fazla işlem yapılmadan, gaz toplama sisteminden kolayca uzaklaştırılabilir. Böylece, metan saflaştırma maliyetlerinden önemli ölçüde tasarruf edilebilir. Birçok araştırma, iki aşamalı sistemin daha kısa bekletme süreleri veya daha yüksek VS bozunma değerleri nedeniyle, tek aşamalı 
sistemden daha iyi olduğunu göstermiştir. Bununla birlikte, hammadde içerisindeki düşük (TS $<\%$ 3) katı içeriği ile iki aşamalı sistemin kullanılması, tek aşamalı sistemden daha verimli değildir.

Üç aşamalı fermentasyon sistemi, atık aktif bulamacın fermentasyonu için, iki aşamalı sistemle karşılaştırıldığında, VS azaltma ve biyogaz verimi daha yüksektir. Aslında, üç aşamalı fermentasyon sistemlerinin kullanılması, yüksek yatırım maliyeti, işletme ve bakım gibi birçok olumsuzluğu da beraberinde getirir. $\mathrm{Bu}$ nedenle, üç aşamalı anaerobik fermentasyon sisteminin pilot ölçekteki uygulanmalarını bulmak zordur. Üç aşamalı fermentasyon, ilke olarak tüm fermentasyon aşamalarını optimize etmek için iyi bir fikirdir. Ancak, laboratuvar ölçeğinde bile iki aşamalı fermentasyon sisteminden daha iyi olduğu kanıtlanmamıştır.

Ayrıca, iki aşamalı sistemler gibi, üç aşamalı sisteme gelen atık akımının mekanik bir ön işleme tabi tutulması gerekir (partikül boyutu $<15 \mathrm{~mm}$ ). TS oranını ayarlamak için bazen besleme materyaline en fazla \% 15 oranında su eklenir. CSTR, hidroliz fermentör olarak yaygın olarak kullanılmaktadır. Hidrolizden sonra, hidrolize edilemeyen materyaller birinci tampon tanktan çıkarılır. Burada substratın $\mathrm{pH}$ ve UYA konsantrasyonu, bir sonraki aşama için de ayarlanabilir. İkinci fermentör, böyle bir anaerobik askıda büyütme işlemini gerçekleştirir. Bu nedenle, ikinci fermentör genellikle bir CSTR veya UASB tip fermentördür. Üçüncü fermentöre gelen ikinci fermentörün atığı, pH'ı ve asetik asit konsantrasyonunu kontrol etmek amacıyla bir tampon tankından geçmelidir. Her bir fermentasyon aşaması için ferdamentör tipinin, besleme yönteminin ve sıcaklık fazının seçilmesi, üç aşamalı fermentasyon sistemlerinin karmaşık bir tasarım duruma gelmesine neden olur.

Tek aşamalı yaş düşük hızlı fermentasyon sistemleri, düşük biyogaz verimi ve düşük OYO $\left(0,5-1,6 \quad \mathrm{~kg}\right.$ vs $/ \mathrm{m}^{3}$ gün $)$ ile karakterize edilirler. Çalışma sırasında dış ortam sıcaklığına bağ $l_{1}$ olarak, uzun $\mathrm{BS}=30-60$ gün ve büyük fermentörler gerektirir. Ancak, kolay kullanım ve ucuz yatırım gibi birçok fayda sağlarlar. Ekonomik yararını artırmak için, herhangi bir ön arıtma aşaması gerekmeksizin, sadece biyolojik olarak parçalanabilen ince atık kaynakları (hayvan gübreleri gibi) için uygulanmalıdır. $\mathrm{Bu}$ nedenle, yaş düşük hızlı fermentasyon sistemleri, tarım arazileri bulunan, sıcak iklime sahip, kırsal alanlar için iyi bir çözümdür ve fermentasyon ürünleri tarımsal üretim sürecinde verimi artırmak ve toprak yapısını iyileştirmek amacıyla kullanılabilir.

\section{Sonuç}

Tek aşamalı yaş yüksek hızlı fermentasyon sistemleri, OYO $4-8 \mathrm{~kg}$ Vs $/ \mathrm{m}^{3}$ gün düzeyine kadar olan yaş düşük hızlı sistemlerden çok daha etkilidir. Bununla birlikte, bazen kullanılan ekipman ve ön işlem süreci nedeniyle işlem, düşük hızlı fermentörlerden daha karmaşıktır. Katı içeriği düşük $(<\%$ 3-5) hammaddeler için, UASB, FBR, EBR, EGBR ve CSTR gibi birçok fermentör bu sistemlerde etkin olarak kullanılabilir. TS $>\% 5$ olduğunda, CSTR yaygın olarak kullanılır. Aslında, bu sistemler kanalizasyon atıkları, tarım ürünleri ve endüstriyel atık su fermentasyonu için yaygın olarak uygulanmaktadır. Hayvansal kaynaklı organik atıkların fermentasyonunda da kullanılan çürütücüler de genellikle CSTR tipidir; diğer tipler düşük katı madde ve yüksek çözülebilir KOİ şartlarında daha etkin kullanıldığından hayvansal atıklarda kullanılamazlar. OFMSW gibi katı içeriği yüksek besleme materyali (TS $>\%$ 20) işlemek için de kullanılabilirler.
Ancak, katı içeriği yüksek hammadde kullanılması durumunda seyreltilmesi gerekir. Bu durumda, su tüketimi ve enerji giderleri sistemin sağladığı enerji faydasını önemli ölçüde azaltır.

Tek aşamalı kuru fermentasyon sistemleri, katı içeriği yüksek hammadde (TS $=\% 30-35)$ ve yüksek OYO $\left(15 \mathrm{~kg} \mathrm{vs}_{\mathrm{vs}} / \mathrm{m}^{3}\right.$ gün$)$ durumunda, AD teknolojisi için önemli bir gelişmedir. Katı içeriği çok yüksek hammadde kullanılması durumunda ( $>\%$ 35), hammaddenin seyreltilmesi gerekir. Biyolojik olarak parçalanabilir atıkların büyük bir bölümünü oluşturan OFMSW'nin işlenmesi için çok uygundurlar. Bu sistemler, sürekli veya kesikli çalışma yöntemleri ile ayırt edilebilirler. Sürekli çalışma yönteminin başlıca üstünlükleri şunlardır:

$\checkmark$ Su tüketimi düşüktür.

$\checkmark$ Fermentör küçüktür.

$\checkmark \quad$ Atık su üretimi çok azdır.

$\checkmark$ Ön arıtma işlemi ucuzdur.

$\checkmark$ Atık kalıntısı kompostlama için iyi uygulanabilir durumdadir.

$\checkmark \quad$ Isı enerjisi gereksinimi daha azdır.

$\mathrm{Bu}$ nedenle, kentsel alanlar için sürekli çalışan sistemler uygulanmalıdır. Kesikli sistemleri için, ekipman yatırımı ve çalışması için gerekli maliyetler daha düşüktür. Bununla birlikte, sürekli çalışan sistemlerden çok daha büyük bir alana ihtiyaç vardır ve gaz üretimi değişkendir. Bu nedenle, kesikli sistemler toplu banliyö alanları için mükemmel bir çözümdür.

Çeşitli fermentörlerde, hidroliz ve metanojenez aşamalarının ayrıldığı iki aşamalı AD sistemleri, tek aşamalı sistemlerden daha kısa HBS ve daha yüksek OYO düzeylerine $\left(50 \mathrm{~kg}_{\mathrm{COD}} / \mathrm{m}^{3} / \mathrm{gün}\right.$ düzeyine kadar) sahip olabilir. İki aşamalı $\mathrm{AD}$ sistemlerinin başlıca üstünlükleri şunlardır:

$\checkmark \quad$ Inşaat maliyeti düşüktür.

$\checkmark$ İşletmede esneklik daha fazladır.

$\checkmark$ Daha sağlamdır.

$\checkmark \quad$ Üretilen gazın metan içeriği yüksektir.

$\checkmark \quad$ Fermentasyon verimliliği daha yüksektir.

$\checkmark \quad$ Özellikle düşük C/N $(<10)$ ile etkin olarak çalışırlar.

Hammaddenin katı içeriği için en iyi uygulama aralığı \% 5-15 arasındadır. TS $<\% 5$ olduğunda, tek aşamalı yaş sistemleri kullanmak daha uygun olabilir. TS $>\% 20$ olması durumunda, aşağıdaki işlemler için gerekli enerji miktarı önemli düzeyde artar:

$>$ Besleme materyalinin seyreltilmesi

$>$ Fermentörlerin 1sıtılması

$>$ Materyalin beslenmesi

$\mathrm{Bu}$ nedenle, kuru tek kademeli fermentasyon sistemini kullanmak daha iyidir. İki aşamalı AD sistemleri, endüstriyel atık su için uygundur. Üç aşamalı fermentasyon sistemlerinin verimi, iki aşamalı sistemlere kıyasla iyileştirilmemiştir. Üç aşamalı sistemlerin büyük ölçekli uygulanması aşağıdaki nedenlerle, günümüzde uygun bir seçim değildir:

> İki aşamalı AD sistemlerine kıyasla, daha karmaşık sistemlerdir.

> Yatırım maliyetleri daha yüksektir.

> Bakım ve işletim için daha fazla enerji kullanılır.

Bununla birlikte, üç aşamalı sistemler hala uygun bir teknolojik gelişmedir. Kullanımları ile ilgili maliyetleri azaltmak için daha fazla araştırılmaları gereklidir. 


\section{Kaynakça}

Abbasi, T, Tauseef, S, Abbasi, SA. (2011). Biogas Energy. In: Springer Briefs in Environmental Science. New York: Springer Science and Business Media.

Akyol, Ç, Aydın, S, Ince, O, Ince, B. (2016). A comprehensive microbial insight into single-stage and two-stage anaerobic digestion of oxytetracycline-medicated cattle manure. Chemical Engineering Journal. Vol. 303, 675-684

Burton, FL, Stensel, HD. (2014). Wastewater Engineering: Treatment and Resource Recovery. 5th ed. New York: McGraw-Hill.

Dareioti, MA, Kornaros, M. (2014). Effect of Hydraulic Retention Time (HRT) on the Anaerobic Co-Digestion of Agroindustrial Wastes in a Two-Stage CSTR System. Bioresour. Technol., 167, 407-415.

Deublein, D, Steinhauser, A. (2011). Biogas from Waste and Renewable Resources: An Introduction. Germany: WileyInterscience; 2011.

Duan, N, Dong, B, Wu, B, Dai, X. (2012). High-solid Anaerobic Digestion Of Sewage Sludge Under Mesophilic Conditions: Feasibility Study. Bioresour. Technol.,104, 150-156.

Eryılmaz, T, Yeşilyurt, M, Gökdoğan, O, Yumak, B. (2015). Determination of Biogas Potential from Animal Waste in Turkey: A Case Study for Yozgat Province. Avrupa Bilim ve Teknoloji Dergisi, 2 (4), 106-111. Retrieved from https://dergipark.org.tr/tr/pub/ejosat/issue/45158/565086.

Kanat, G , Erguven, G. (2020). Importance of Solid Waste Management on Composting, Problems and Proposed Solutions: The Case of Turkey. Avrupa Bilim ve Teknoloji Dergisi , (19) , 66-71. DOI: 10.31590/ejosat.672413.

Kayhanian, M, Tchobanoglous, G, Brown, RC. (2007). Biomass Conversion Processes For Energy Recovery. In: Kreith, F., Goswami, DY, eds. Handbook of energy efficiency and renewable energy. Florida: CRC Pres, p. 22.1-22.67.

Kim, M, Gomec, CY, Ahn, Y, Speece, R. (2003). Hydrolysis and Acidogenesis of Particulate Organic Material in Mesophilic and Thermophilic Anaerobic Digestion. Environ. Technol. 2003;24: 1183-1190.

Kocabey, S. (2019). Balıkesir İli İçin Hayvansal Atık Kaynaklı Biyogaz Potansiyelinin Belirlenmesi. Avrupa Bilim ve Teknoloji Dergisi , (17), 234-243. DOI: 10.31590/ejosat.619058.

Komemoto, K, Lim, YG, Nagao, N, Onoue, Y, Niwa, C, Toda, T. (2009). Effect of Temperature on UYA's and Biogas Production in Anaerobic Solubilization of Food Waste. Waste Manage., 29, 2950-2955.

Kozuchowska, J, Evison, LM. (1995). UYA Production in Preacidification Systems without pH Control. Environ. Technol., 16, 667-675.

Li, W, Guo, J, Cheng, H, Wang, W, Dong, R. (2017). Two-phase Anaerobic Digestion of Municipal Solid Wastes Enhanced by Hydrothermal Pretreatment: Viability, Performance and Microbial Community Evaluation. Appl. Energy, 189, 613622.

Lindner, J, Zielonka, S, Oechsner, H, Lemmer, A. (2015). Effect of Different Ph-Values on Process Parameters in Two-Phase Anaerobic Digestion of High-Solid Substrates. Environ. Technol., 36, 198-207

Lissens, G, Vandevivere, P, De Baere, L, Biey, E, Verstraete, W. (2001). Solid Waste Digestors: Process Performance and Practice for Municipal Solid Waste Digestion. Water Sci. Technol., 44, 91-102.
Moestedt, J, Nordell, E, Hallin, S, Schnürer, A. (2016). Two-Stage Anaerobic Digestion for Reduced Hydrogen Sulphide Production. J. Chem. Technol. Biotechnol., 91, 1055-1062.

Nakakubo, R, Møller, HB, Nielsen, AM, Matsuda, J. (2008). Ammonia inhibition of methanogenesis and identification of process indicators during anaerobic digestion. Environ. Eng. Sci., 25, 1487-1496.

Nayono, SE. 2010 Anaerobic Digestion of Organic Solid Waste for Energy Production [dissertation]. Germany: Karlsruhe Institute of Technology.

Paudel, S, Kang, Y, Yoo, YS, Seo, GT. (2017). Effect of Volumetric Organic Loading Rate (OLR) on H2 and CH4 Production by Two-Stage Anaerobic Co-Digestion of Food Waste And Brown Water. Waste Manage., 61:484-493.

Pavan, P, Battistoni, P, Cecchi, F, Mata-Alvarez, J. (2000) TwoPhase Anaerobic Digestion of Source Sorted OFMSW (Organic Fraction Of Municipal Solid Waste): Performance and Kinetic Study. Water Sci. Technol., 41, 111-118.

Ramos-Suárez, J, Arroyo, NC, González-Fernández, C. (2015). The Role of Anaerobic Digestion in Algal Biorefineries: Clean Energy Production, Organic Waste Treatment, and Nutrient Loop Closure. In: Singh B, Kuldeep B, Faizal B, eds. Algae and environmental sustainability. India: Springer; $\mathrm{p}$. 53-76.

Rapport, J, Zhang, R, Jenkins, BM, Williams, RB. (2008). Current Anaerobic Digestion Technologies Used for Treatment of Municipal Organic Solid Waste. In: California Environmental Protection Agency. California: California Integrated Waste Management Board.

Rincón, B, Borja, R, González, JM, Portillo, MC, Sáiz-Jiménez, C. (2008). Influence of Organic Loading Rate and Hydraulic Retention Time on the Performance, Stability and Microbial Communities of One-Stage Anaerobic Digestion of TwoPhase Olive Mill Solid Residue. Biochem. Energ. J., 40, 253261.

Roos, K, Martin, J, Moser, M. (2004). AgSTAR handbook: A Manual for Developing Biogas Systems at Commercial Farms in the United States. US EPA.

Rosgaard, L, Andric, P, Dam-Johansen, K, Pedersen, S, Meyer, AS. (2007). Effects of Substrate Loading on Enzymatic Hydrolysis and Viscosity of Pretreated Barley Straw. Appl. Biochem. Biotechnol., 143, 27-40.

Stewart, WC. (2014). Three Stage, Multiple Phase Anaerobic Digestion System and Method [Internet]. Google Patents.

Tchobanoglous, G, Burton, FL, Stensel, HD. (2003). Wastewater Engineering: Treatment and Reuse. New York: McGraw-Hill Education.

Turker, G. (2020). Organik Atıklardan Biyogaz Üretimi, Lambert Academic Publishing

Turovskiy, IS, Mathai, P. (2006). Wastewater Sludge Processing. New Jersey: Wiley-Interscience.

Uemura, S. (2010). Mineral Requirements for Mesophilic and Thermophilic Anaerobic Digestion of Organic Solid Waste. Int. J. Environ. Res., 4, 33-40.

Yen, HW, Brune, DE. (2007). Anaerobic Co-Digestion of Algal Sludge And Waste Paper to Produce Methane. Bioresour. Technol., 98,130-134.

Yu, HQ, Fang, HHP. (2002). Acidogenesis of Dairy Wastewater at Various pH Levels. Water Sci. Technol., 45, 201-206.

Yu, L, Ma, J, Frear, C, Zaher, U, Chen, S. (2013). Two-Stage Anaerobic Digestion Systems Wherein One of the Stages Comprises A Two-Phase System. Google patents. 
Zenk, H. (2019). Samsun İlinin Hayvan Gübrelerinden Üretilebilecek Elektrik Enerji Potansiyeli. Avrupa Bilim ve Teknoloji Dergisi , (17) , 1307-1312 . DOI: 10.31590/ejosat.661910

Zhang, J., Loh, K-C., Li, W., Lim, JW., Dai, Y., Tong, YW. (2016). Three-Stage Anaerobic Digester for Food Waste. Appl. Energ., 194, 287-295.

Zhang, J, Sun, K, Wu, M, Zhang, L. (2006). Influence of Temperature on Performance of Anaerobic Digestion of Municipal Solid Waste. J. Environ. Sci., 18, 810-815 